\title{
Monitoramento da qualidade de águas em programas de pagamento por serviços ambientais hídricos: estudo de caso no município de São José dos Campos/SP
}

\author{
Water quality monitoring in payment for environmental \\ services programs: case study in São José dos Campos/SP
}

Fabiana Alves Fiore', Vivian Silveira dos Santos Bardini², Ricardo Carneiro Novaes ${ }^{3}$

\begin{abstract}
RESUMO
Na última década, verificou-se, no Brasil, o aumento do número de programas de Pagamento por Serviços Ambientais (PSA) voltados à conservação quanti-qualitativa de águas nos territórios. Entre as principais demandas de aprimoramento desses programas, está a necessidade de comprovação dos serviços ecossistêmicos prestados. É nesse contexto que o presente trabalho foi desenvolvido com o objetivo de avaliar as diretrizes norteadoras do monitoramento da qualidade das águas em bacias contempladas por PSA, bem como verificar a aplicabilidade dessas medidas para a microbacia do Ribeirão das Couves, em São José dos Campos, São Paulo. Para a realização desta pesquisa, utilizou-se, além da pesquisa bibliográfica exploratória sobre a temática, investigação histórica dos documentos da Secretaria Municipal de Meio Ambiente e análise dos dados mensais de qualidade de água fornecidos pela concessionária municipal. A partir dos resultados foi possível verificar que, na atualidade, as águas do Ribeirão das Couves não atendem aos limites da Classe 1 para o parâmetro Escherichia coli. Em suas diferentes fases, o PSA demanda condições de monitoramento diferenciadas em relação ao número de pontos de amostragem e à frequência das análises. Por fim, mesmo entendendo como essencial a caracterização de todos os parâmetros que compõem o Índice de Qualidade de Águas (IQA), este trabalho evidenciou um conjunto mínimo de indicadores para a avaliação dos incrementos de qualidade de águas em bacias contempladas por PSA.
\end{abstract}

Palavras-chave: pagamento por serviços ambientais; monitoramento; qualidade de águas; Ribeirão das Couves.

\begin{abstract}
In the last decade, it was found in Brazil an increase in the number of Payment for Environmental Services (PES) programs focused on quantitative and qualitative conservation of waters in the territories. Among the main demands for improvement of these programs, there is a need to proof the provided ecosystem services. It is in this context that the present research was developed to evaluate the directives of water quality monitoring in watershed covered by PES and to assess the applicability of these to the watershed of the Couves Stream in São José dos Campos, São Paulo. For this applied research, besides the bibliographical research on the subject, a historical research in the documents of the Municipal Secretary of Environment and a monthly analysis of the water quality data provided by municipal utility were performed. From the results, it was verified that, at present, the Couves Stream waters do not meet the limits of Class 1 for the parameter Escherichia coli. At its various stages, PES demands differentiated monitoring conditions in relation to the number of sampling points and the frequency of analysis. Finally, even understanding the characterization of all parameters that compose the Water Quality Index (WQI) as essential, this study showed a minimum set of indicators for assessing the increases of water quality in watersheds covered by PES.
\end{abstract}

Keywords: payment for environmental services; monitoring; water quality; Couves Stream.

\footnotetext{
'Doutora em Saneamento e Meio Ambiente pela Faculdade de Engenharia Civil, Arquitetura e Urbanismo da Universidade Estadual de Campinas (UNICAMP). Professora do Instituto de Ciência e Tecnologia da Universidade Estadual Paulista "Júlio de Mesquita Filho" (UNESP) - São José dos Campos (SP), Brasil. 2Pós-Doutora em Engenharia de Transportes pelo Departamento de Transportes da Escola de Engenharia de São Carlos da Universidade de São Paulo (USP). Professora do Instituto de Ciência e Tecnologia da UNESP - São José dos Campos (SP), Brasil. ${ }^{3}$ Pós-Doutor em Educação pela Faculdade de Educação da USP. Freshwater Specialist do Programa de Ciências WWF - São Paulo (SP), Brasil. Endereço para correspondência: Fabiana Fiore - Rodovia Presidente Dutra, km 137,8 - Eugênio de Melo - 12247-004 - São José dos Campos (SP), Brasil E-mail: fabiana.fiore@ict.unesp.br Recebido: 08/06/16 - Aceito: 20/10/16 - Reg. ABES: 362773
} 


\section{INTRODUÇÃO}

A história da implementação de programas, projetos e políticas de Pagamento por Serviços Ambientais Hídricos (PSA-H) no Brasil é recente, com atividades e regramento legal datados a partir dos anos 2000. De acordo com Novaes (2014), por se tratar de uma abordagem relativamente nova, o desenvolvimento teórico e a execução das atividades de Pagamento por Serviços Ambientais (PSA) ainda estão sendo aperfeiçoados.

No PSA-H, o usuário paga ao provedor pelos serviços de quantidade e qualidade das águas, decorrentes de boas práticas ambientais adotadas pelo detentor em seu território. No Brasil, essas boas práticas estão relacionadas ao atendimento de requisitos legais, tais como a proteção e a recuperação de áreas de preservação permanente (APPs), a adequação ambiental das propriedades rurais e a minimização dos impactos de atividades rurais, por meio do controle de processos erosivos, da adoção de tecnologias de saneamento e da recuperação de áreas degradadas (BRASIL, 2012; ANA, 2013; JARDIM \& BURSZTYN, 2015).

Considerado que o PSA corresponde a uma transação voluntária na qual pelo menos um comprador adquire do provedor um serviço ambiental bem definido ou um uso da terra que possa assegurar esse serviço, é necessário que a provisão dos serviços seja garantida (WUNDER, 2005). Dessa forma, o monitoramento das condições pactuadas pode ser entendido como condição estruturante dos programas de PSA. Entretanto, de acordo com Branco e Ruiz (2015), a grande lacuna dos sistemas de PSA-H implantados no país reside no fato de poucos deles possuírem sistemas de monitoramento funcionando plenamente.
Uma vez que não existe acordo científico sobre o conteúdo mínimo dos planos de monitoramento de PSA, diferentes padrões estão sendo desenvolvidos, com o intuito de viabilizar a comparação entre as iniciativas de implantação e operação no país. Entre elas, destacam-se: o Manual Operativo da Agência Nacional de Águas (ANA, 2012a); o Protocolo de Indicadores de Impacto Ambiental e Socioeconômico para Projetos de Pagamento por Serviços Ambientais - Metodologia Oásis (FUNDAÇÃO GRUPO BOTICÁRIO DE PROTEÇÃO À NATUREZA, 2014) —; o Protocolo de Monitoramento de Água e Solos - Programa Produtor de Água (TNC, 2011) —; e o Programa de Pagamento por Serviços Ambientais - PRO-PSA (AGEVAP, 2015).

Nos programas de PSA-H implantados no território brasileiro, é possível verificar a existência de monitoramento da fauna e da flora, bem como da quantidade e da qualidade das águas. De acordo com Novaes (2014), 56\% dos PSAs com foco em águas no Brasil monitoram a qualidade e a quantidade de águas. Segundo Lima et al. (2015), no entanto, as lacunas do monitoramento de PSA-H no Brasil são referentes a parâmetros analisados, frequência de monitoramento e ausência de apoio técnico para a instalação e manutenção de equipamentos no campo. Além disso, diversos programas não possuem dados anteriores à aplicação do projeto, o que impossibilita a avaliação de desempenho (LIMA et al., 2013).

A alteração da qualidade da água nos PSA-H brasileiros, objeto de estudo do presente trabalho, vem sendo monitorada por meio de parâmetros diversos, conforme mostra o Quadro 1.

A partir da análise do Quadro 1, é possível verificar que os indicadores de qualidade das águas adotados nos projetos de PSA-H são

Quadro 1 - Parâmetros de qualidade de águas monitorados em unidades de Pagamento por Serviços Ambientais Hídricos brasileiras.

\begin{tabular}{|c|c|c|c|c|}
\hline Cases & Pontos de amostragem & Período de monitoramento & Parâmetros & Frequência \\
\hline $\begin{array}{l}\text { AGEVAP (2015) } \\
\text { PRO-PSA Guandu }\end{array}$ & $\begin{array}{c}3 \text { pontos: } 1 \text { na cabeceira } \\
\text { para referência; } 1 \text { na área } \\
\text { de intervenção e } 1 \text { na foz } \\
\text { ou } \\
1 \text { ponto na exutória para } \\
\text { áreas de até } 100 \text { ha }\end{array}$ & $\begin{array}{l}\text { Iniciar antes das } \\
\text { atividades de campo }\end{array}$ & $\begin{array}{l}\text { Mínimos: turbidez e sólidos em suspensão; } \\
\text { Desejáveis: pH, DBO, coliformes } \\
\text { termotolerantes, nitrogênio e fósforo totais }\end{array}$ & $\begin{array}{c}\text { Não } \\
\text { determinada }\end{array}$ \\
\hline $\begin{array}{l}\text { TNC (2013) } \\
\text { TR para o monitoramento } \\
\text { do Rio Camburiú }\end{array}$ & 5 pontos em 200 ha & 2 anos & $\begin{array}{l}\text { Temperatura, pH, condutividade, turbidez, } \\
\text { sólidos em suspensão total, cor, matéria } \\
\text { orgânica, nitrogênio total, nitrogênio } \\
\text { amoniacal, nitratos, nitritos, fósforo total }\end{array}$ & Quinzenal \\
\hline $\begin{array}{l}\text { Conservador de águas } \\
\text { (PEREIRA, 2012) }\end{array}$ & --- & --- & $\begin{array}{l}\text { Temperatura, condutividade, turbidez, } \\
\text { oxigênio dissolvido e pH }\end{array}$ & Bimestral \\
\hline $\begin{array}{l}\text { FUNDAÇÃO GRUPO } \\
\text { BOTICARIO DE PROTEÇÃO } \\
\text { A NATUREZA. (2O14)) }\end{array}$ & --- & --- & $\begin{array}{l}\text { Condutividade elétrica; } \\
\text { oxigênio dissolvido e turbidez }\end{array}$ & $\begin{array}{c}\text { Não } \\
\text { determinada }\end{array}$ \\
\hline $\begin{array}{l}\text { CASTELLO BRANCO (2015) } \\
\text { Bacia do Rio das Pedras }\end{array}$ & 2 pontos em 5.000 ha & & $\begin{array}{l}\mathrm{pH} \text {, turbidez, } \mathrm{DBO} \text {, cor, coliformes } \\
\text { termotolerantes, oxigênio dissolvido, nitrogênio } \\
\text { amoniacal, fósforo total, temperatura }\end{array}$ & Semestral \\
\hline
\end{tabular}

AGEVAP: Agência de Bacia do Vale do Paraíba; TNC: The Nature Conservancy; PRO-PSA: Programa de Pagamento por Serviços Ambientais DBO: demanda biológica de oxigênio; TR: Termo de Referência. 
semelhantes aos que integram o Índice de Qualidades de Águas (IQA) e que também estão contemplados pelo ordenamento jurídico brasileiro para a avaliação da condição da qualidade de uso seguro das águas superficiais. No entanto, diversos autores (FARLEY \& COSTANZA, 2010; MURADIAN et al., 2010; MATTOS \& HERCOWITZ, 2011; MARSHALL, 2013; LIMA et al., 2015) salientam que os altos custos de monitoramento fazem com que as análises sejam realizadas de modo experimental por instituições parceiras dos projetos. Dessa forma, a redução do número de parâmetros avaliados, assim como as descontinuidades, acarretam inconsistência nas informações sobre os programas implementados (BRASIL, 2005; 2013).

As especificidades de cada projeto de PSA-H e dos territórios determinam a necessidade de personalização dos planos de monitoramento. No entanto, a existência de padronização permite que avaliações comparativas sejam realizadas e que os recursos sejam devidamente alocados e garantam o melhor desempenho possível (ANA, 2013; JARDIM \& BURSZTYN, 2015).

Este projeto foi conduzido no contexto de implementação de um PSA-H na microbacia do Ribeirão das Couves, localizada no município de São José dos Campos, São Paulo, visando o estabelecimento de diretrizes para a elaboração do plano de monitoramento do referido PSA-H. Assim sendo, a pesquisa foi desenvolvida para responder às seguintes questões:

- Qual a qualidade atual das águas na microbacia?

- Por quanto tempo as águas devem ser monitoradas?

- Quais os critérios para a alocação dos pontos de monitoramento?

- Quais parâmetros são relevantes para o monitoramento de qualidade das águas?

- Com que frequência a amostragem deve ser realizada?

\section{METODOLOGIA}

Este trabalho é fruto de uma pesquisa exploratória aplicada, que fez uso de dados quanti-qualitativos para a realização de classificações comparativas e análise da condição da qualidade da água no território (LEITE, 2008; MINAYO; ASSIS; SOUZA, 2005; BAUER \& GASKELL, 2002). A investigação histórica, com recorte espacial no território de São José dos Campos, São Paulo, foi realizada por meio de pesquisa documental nos arquivos da Secretaria Municipal de Meio Ambiente (SEMEA) e nos documentos disponibilizados pelas organizações parceiras do projeto.

Os dados referentes à qualidade das águas na microbacia do Ribeirão das Couves foram obtidos por meio dos laudos mensais de análise das águas brutas, entre 2010 e 2016, da Companhia de Saneamento Básico do Estado de São Paulo (SABESP) - concessionária dos serviços de água e esgoto no município de São José dos Campos. De acordo com os laudos cedidos pela SABESP, as amostras foram coletadas conforme método 1060 do Standard Methods for the Examination of Water and Wastewater (APHA, 1998) e as análises realizadas em laboratório da própria instituição (acreditado pelo Instituto Nacional de Metrologia, Qualidade e Tecnologia [INMETRO]), em conformidade com os métodos específicos apresentados no Quadro 2.

O Decreto Estadual Paulista n. 10.755 (GOVERNO DO ESTADO DE SÃO PAULO, 1977) classifica os afluentes do Rio Jaguari, inclusive o Ribeirão das Couves, como da Classe 1. Vale ressaltar que os usos referentes à Classe 1 no Estado de São Paulo (GOVERNO DO ESTADO DE SÃO PAULO, 1976) são equivalentes aos da Classe Especial de águas doces do âmbito federal (BRASIL, 2005).

Uma vez que não existem padrões para as águas de classe especial, já que nessas as condições naturais devem ser mantidas, são vedados o lançamento de efluentes ou a disposição de resíduos, mesmo que tratados, nessas águas (BRASIL, 2011a). Assim, como o solo da microbacia em estudo é usado para agricultura e pecuária, os padrões de classe da Resolução no 357 do Conselho Nacional do Meio Ambiente (CONAMA [BRASIL, 2005]) foram aqui tratados exclusivamente como referência das condições da qualidade do recurso hídrico.

As estratégias para o monitoramento das águas da microbacia objeto do PSA foram propostas a partir de metanálise da produção científica sobre o monitoramento das unidades de PSA-H implantadas no Brasil e dos requisitos estabelecidos pelo Programa Nacional de Avaliação da Qualidade das Águas (ANA, 2013). Considerada a necessidade de aceitação dos indicadores pelos gestores locais (GALLOPIN, 1996), a proposição foi submetida à câmara técnica de monitoramento do PSA, que tem representantes de instituições de ensino e pesquisa (Universidade Estadual Paulista "Júlio de Mesquita Filho", UNESP, e Instituto Tecnológico de Aeronáutica, ITA), da Agência de Bacia do Vale do Paraíba (AGEVAP), da SEMEA de São José dos Campos e da SABESP.

\section{RESULTADOS}

\section{Contextualização}

A microbacia do Ribeirão das Couves localiza-se na área de proteção ambiental (APA) de São Francisco Xavier e compõe o mosaico de

Quadro 2 - Métodos utilizados para a realização das análises.

\begin{tabular}{|l|c|}
\hline Ensaio & Método \\
\hline Coliformes totais & Substrato Enzimático/SMEWW - 9223 B \\
\hline Cor aparente & Comparação Visual/SMEWW - 2120 B \\
\hline E. Coli & Substrato Enzimático/SMEWW - 9223 B \\
\hline $\mathrm{pH}$ & Eletrométrico/SMEWW 4500-H+ B \\
\hline Turbidez & Nefelométrico/SMEWW 2130 B \\
\hline
\end{tabular}


unidades de conservação da Serra da Mantiqueira (GOVERNO DO ESTADO DE SÃO PAULO, 2002). Grande parte de seus 774 ha pertence à zona de conservação de recursos hídricos municipal, que visa garantir o provimento quanti-qualitativo de águas para o abastecimento público.

A microbacia do Ribeirão das Couves foi eleita como projeto-piloto do Programa Municipal de Pagamento por Serviços Ambientais de São José dos Campos, pois abastece diretamente 4.000 habitantes do distrito de São Francisco Xavier e está localizada em APA da sub-bacia do Rio do Peixe - principal tributário do Reservatório Jaguari. Além disso, a microbacia apresenta área de declividade extremamente acentuada, riscos geotécnicos e vulnerabilidade de perda de solo (SÃO JOSÉ DOS CAMPOS, 2014).

De acordo com levantamento de campo realizado por técnicos da SEMEA de São José dos Campos (2014), as 52 nascentes existentes na microbacia são perenes. Com relação às características das APPs, as nascentes da microbacia foram classificadas como:

- preservadas, em que foram observadas formações Floresta Ombrófila Densa Montana (FODM) e Floresta Ombrófila Densa Alto-Montana (FODAM), em estágios avançado e médio;

- perturbadas, quando na área se verificava FODM e FODAM em estágio inicial, devido à retirada de pinus;

- degradadas, quando estavam em área de pastagem, entorno de edificações, estradas, solo exposto ou em reflorestamento.

A partir dessa classificação, a SEMEA identificou que na área 52\% das nascentes tinham APPs preservadas e apenas $23 \%$ podiam ser consideradas degradadas, conforme o mapa da Figura 1.

As águas da microbacia do Ribeirão das Couves são utilizadas para o abastecimento público dos moradores do distrito de São Francisco Xavier. A captação para abastecimento ocorre nas proximidades da Estação de Tratamento de Água (ETA) que se localiza a jusante das propriedades abarcadas pelo programa de PSA, conforme mostrado na Figura 1.

Em atendimento aos requisitos legais em vigor, em especial à Portaria da Agência Nacional de Vigilância Sanitária (ANVISA [BRASIL, 2011b]), que dispõe sobre os procedimentos de controle e vigilância da qualidade da água para o consumo humano e seu padrão de potabilidade, a SABESP realiza periodicamente o monitoramento da água captada. Entre as análises mensalmente realizadas pela SABESP, serão apresentados os dados de $\mathrm{pH}$, cor, turbidez, coliformes totais e Escherichia coli para a caracterização da qualidade atual das águas.

\section{A qualidade da água na microbacia do Ribeirão das Couves}

Valores de $\mathrm{pH}$ afastados da neutralidade podem afetar a vida aquática (VON SPERLING, 2005). Em vista disso, para todas as classes estabelecidas pela Resolução CONAMA n 357/2005, os valores devem estar entre 6,0 e 9,0. Conforme a Figura 2, em apenas uma das amostras o pH do Ribeirão das Couves apresentou valor inferior a 6,0 $(\mathrm{pH}=5,7$, em janeiro de 2011). Nas demais medições, o pH oscilou entre 6,7 e 8,1 dentro da faixa limite preconizada pela Resolução CONAMA no $357 / 2005$.

Pode-se notar que 98,3\% dos resultados de $\mathrm{pH}$ mostraram valores entre 6,7 e 8,1; o que caracteriza as águas do Ribeirão das Couves como neutras ou levemente básicas. A baixa dispersão dos dados e a inexistência de tendências sazonais não permitem inferências sobre os períodos secos e chuvosos. Em janeiro, mês mais chuvoso na região, o pH é ligeiramente menor em $83,0 \%$ das amostras, diminuição que pode estar relacionada ao carreamento de matéria orgânica presente no território para os recursos hídricos tributários do Ribeirão das Couves.

No período monitorado, o Ribeirão das Couves apresentou a variação de cor mostrada na Figura 3. Em geral, a presença de cor em águas naturais é atribuída à decomposição de matéria orgânica, tanto de origem vegetal quanto animal, e à presença de íons metálicos naturais, como o ferro e o manganês. A presença de cor nas águas pode suprimir os processos fotossintéticos e alterar significativamente os cursos d'água. Além disso, de acordo com De Julio et al. (2006), a presença de substâncias húmicas pode conferir características indesejáveis às águas de abastecimento.

O limite de cor estabelecido para as Classes 2 e 3 é o mesmo, de $75 \mathrm{mg}$ Pt/L ou UC, mas é referente à cor verdadeira. Nos valores de cor apresentados na Figura 3 podem estar contidos sólidos em suspensão que conferem turbidez às águas; no entanto, mesmo tratando-se de cor aparente, a média dos valores observados no recurso hídrico é inferior ao padrão de potabilidade brasileiro.

Os valores de turbidez encontrados nas águas do Ribeirão das Couves são baixos (Figura 4), apesar da existência de pastagem em cerca de $20 \%$ da área da bacia. Considerando que o terreno da microbacia é altamente declivoso e que a porção degradada é aquela localizada no terço final da bacia, é possível justificar tais dados pela não ocorrência de processos erosivos intensos nesse período ou ainda pela capacidade de detenção de sedimentos pelos barramentos implantados nas propriedades particulares.

A média dos valores de turbidez encontrados no Ribeirão das Couves é muito inferior ao padrão das classes e aproxima-se dos limites de potabilidade de água estabelecidos no Brasil (BRASIL, 2011b). No entanto, mesmo não havendo concentrações expressivas de sólidos suspensos nessas águas, há presença de coliformes totais.

As bactérias do grupo coliforme incluem espécies de origem não exclusivamente fecal, que ocorrem naturalmente no solo, na água e em plantas (OMS, 1995), por isso não foram listadas como indicadores diretos da qualidade das águas pela Resolução CONAMA n 357/2005. 


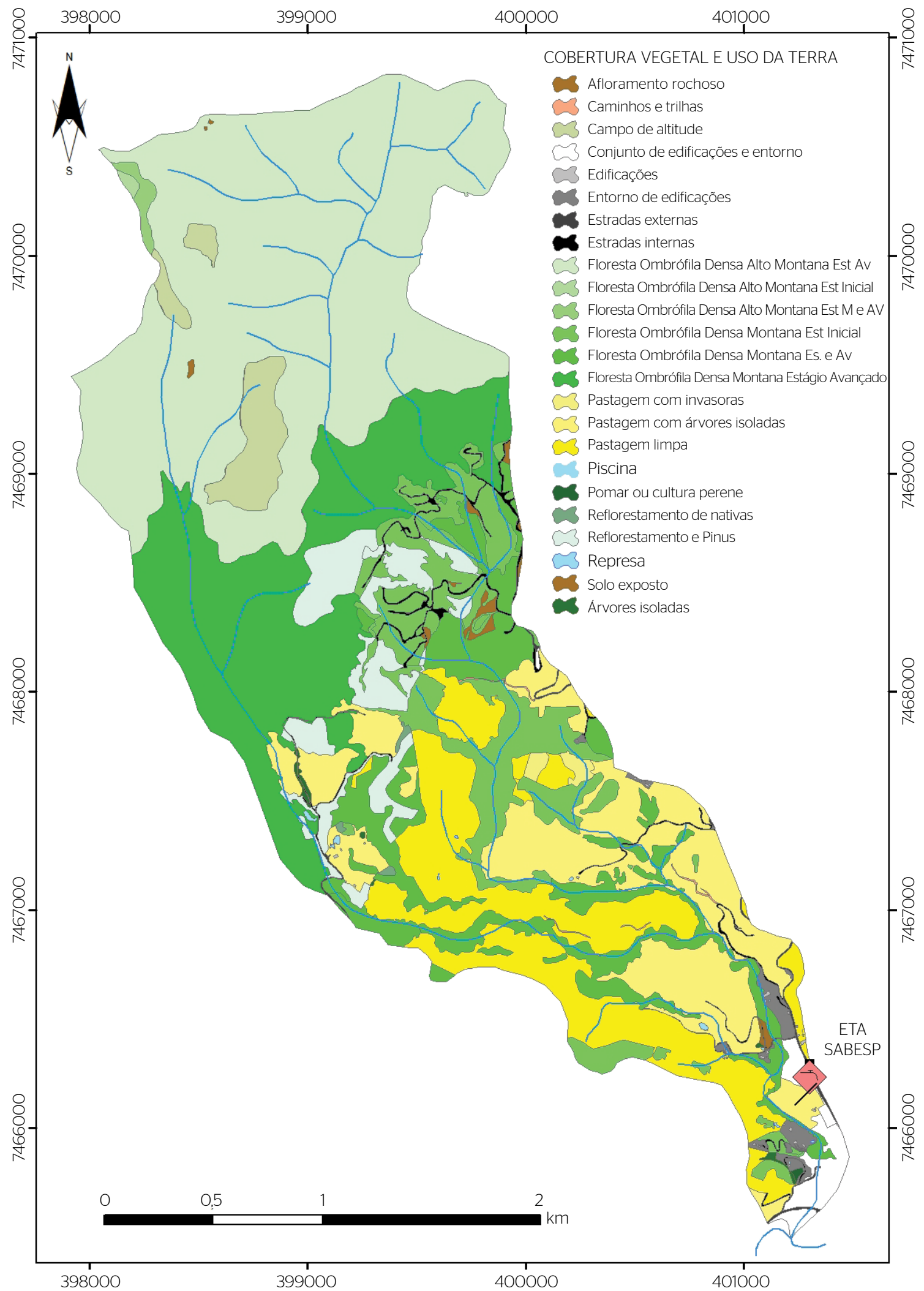




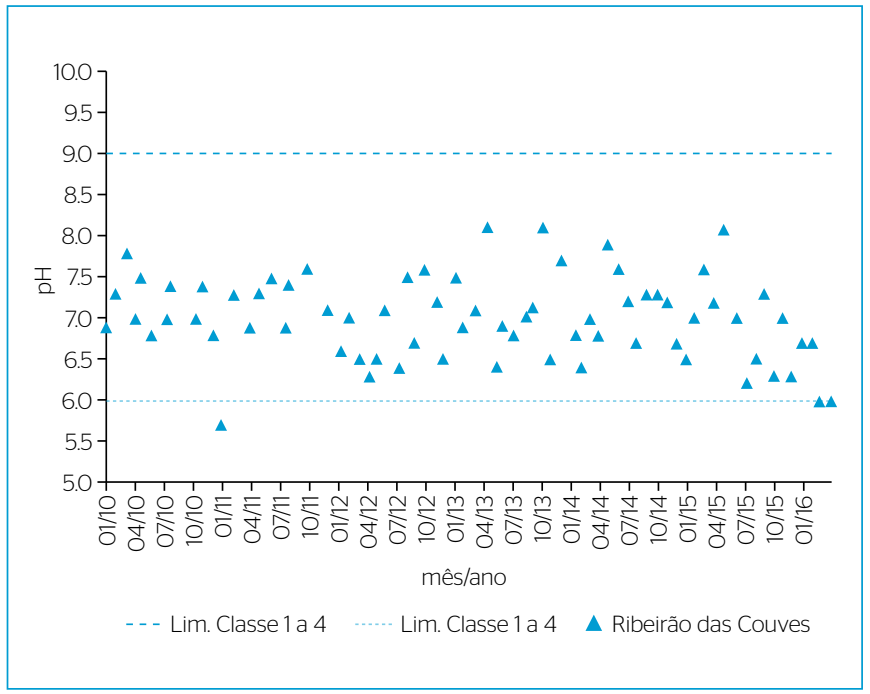

Figura 2 - Valores de pH nas águas do Ribeirão das Couves.

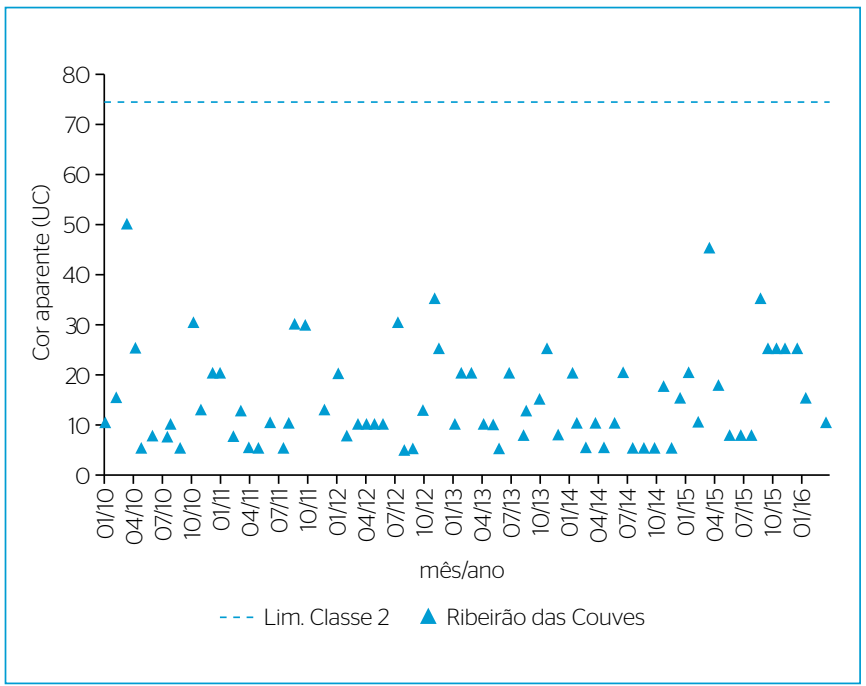

Figura 3 - Cor aparente das águas do Ribeirão das Couves.

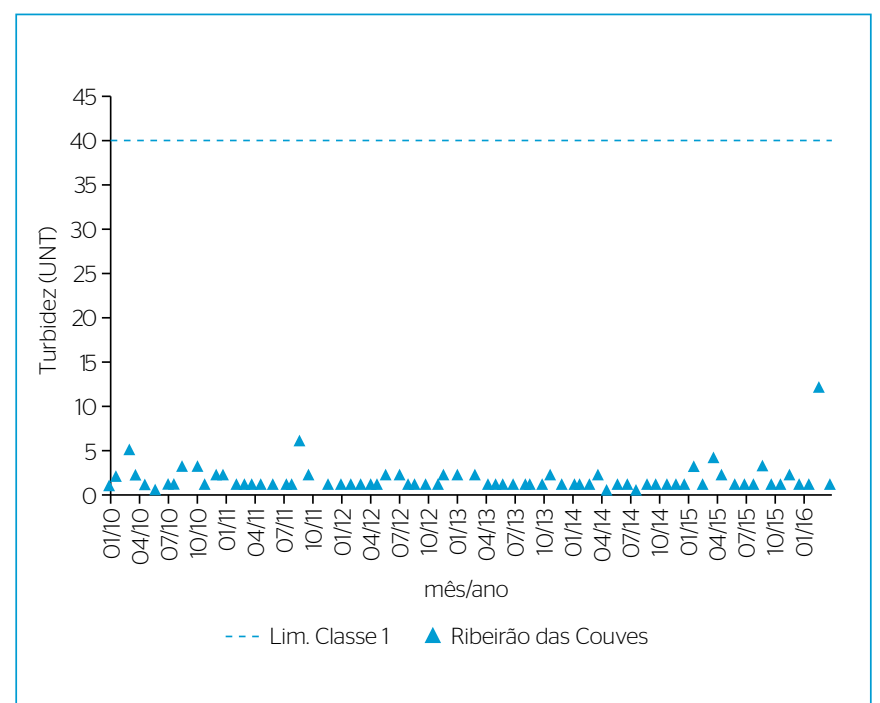

Figura 4 - Turbidez das águas do Ribeirão das Couves.
O parâmetro coliformes totais, no entanto, continua sendo utilizado para o controle da qualidade das águas de abastecimento público (ANVISA, 2011). Considerando a relação de coliformes totais e fecais de CT=5xCF trazida pela Resolução CONAMA n 20/1986 (BRASIL, 1986) e os limites vigentes (BRASIL, 2005) para os microrganismos termotolerantes, os dados foram avaliados para as Classes 1 e 2, como mostrado na Figura 5.

Os dados evidenciam que a condição microbiológica da qualidade dessas águas não atende nem mesmo aos padrões estabelecidos para a Classe 2 (BRASIL, 2005). A concentração de coliformes termotolerantes, indicativos da presença de fezes humanas ou de animais homeotérmicos, é elevada nas águas da microbacia, principalmente se considerado que pouco mais de $20 \%$ de sua área é recoberta por pastagem, sendo uma atividade pecuária de pequeno porte e de baixa produtividade.

Vale ressaltar que o limite da qualidade da Classe 2 é o mesmo determinado para a dessedentação de animais criados confinados e que o valor médio de coliformes termotolerantes no Ribeirão das Couves, no período monitorado, é muito próximo do limite legalmente estabelecido para o uso recreativo de contato secundário (Classe 3).

De acordo com a Resolução CONAMA no 357/2005, a E. Coli é a única espécie do grupo dos coliformes termotolerantes cujo habitat exclusivo é o intestino humano e de animais homeotérmicos, em que ocorre em densidades elevadas. Em vista disso, pode ser utilizada como parâmetro de qualidade microbiológica, em substituição aos coliformes termotolerantes, de acordo com limites estabelecidos pelo órgão ambiental competente.

No Estado de São Paulo, a Companhia Ambiental do Estado de São Paulo (CETESB), por meio de relatório técnico elaborado em 2008 (SATO et al., 2008), recomendou o uso conservativo da correlação de 1 coliforme termotolerante para 0,6 de E. Coli. Considerada essa

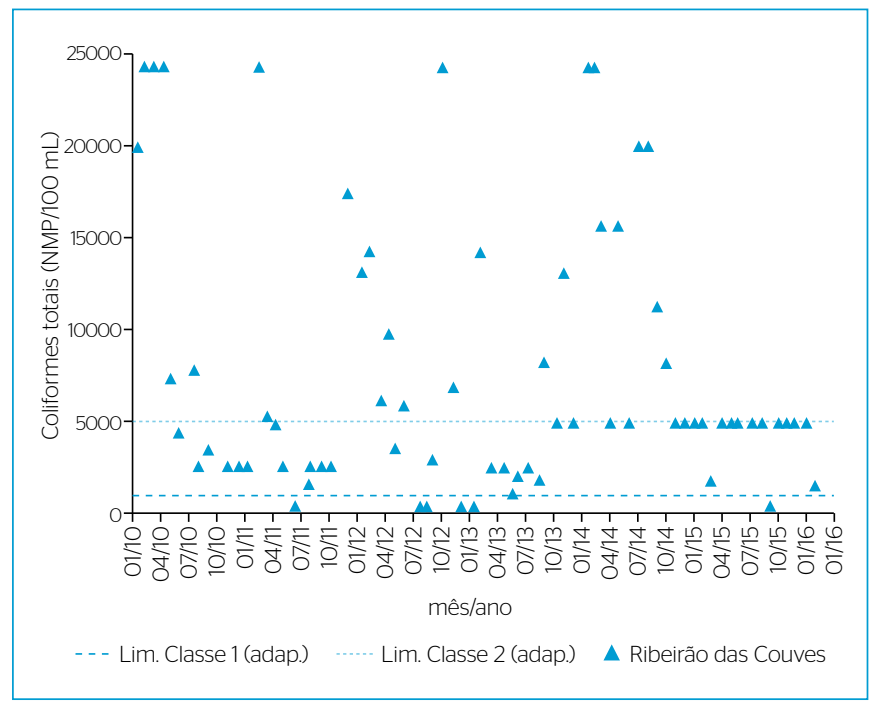

Figura 5 - Coliformes totais presentes nas águas do Ribeirão das Couves. 
correlação, os limites de E. Coli para as Classes 1 e 2, de acordo com a Resolução CONAMA no 357/2005, no Estado de São Paulo são de 120 e 600, respectivamente.

No Ribeirão das Couves, o parâmetro E. Coli se tornou frequente nos laudos mensais de qualidade a partir de julho de 2012. Vale ressaltar que até o ano de 2011 o uso do parâmetro E. Coli, por limitações técnicas e econômicas, era apenas recomendado como indicador preferencial de qualidade de água potável no Brasil (BRASIL, 2004). Os dados de E. Coli presentes no recurso hídrico em estudo estão apresentadas Figura 6, e mostram que, em média, essas águas possuem condição de qualidade microbiológica dentro dos limites da Classe 2.

As médias geométricas anuais de E. Coli/ $100 \mathrm{~mL}$ encontradas no Ribeirão das Couves, de 2010 a 2015, foram de: 160,3; 86,9; 165,0; 437,8. Esses valores dispensam o monitoramento de cistos de Giardia spp. e oocistos de Cryptosporidium spp. nesse ponto de captação de água utilizado para abastecimento público do distrito de São Francisco Xavier (BRASIL, 2011b).

\section{ESTRATÉGIAS PARA A DETERMINAÇÃO DO PLANO DE MONITORAMENTO}

As unidades de PSA-H implantadas no país possuem estruturas distintas, determinadas, em geral, pelos provedores de recursos financeiros. Nesses programas, é possível verificar a existência de quatro fases/etapas distintas, com demandas específicas de monitoramento; são elas: Diagnóstico preliminar, Planejamento, Implantação e Operação (PAGIOLA; GLEHN; TAFARELLO, 2012).

O diagnóstico preliminar que permite a identificação das áreas nas quais o PSA-H será implantado contempla a caracterização dos usos do território e das qualidades atual e prevista para as águas, além de

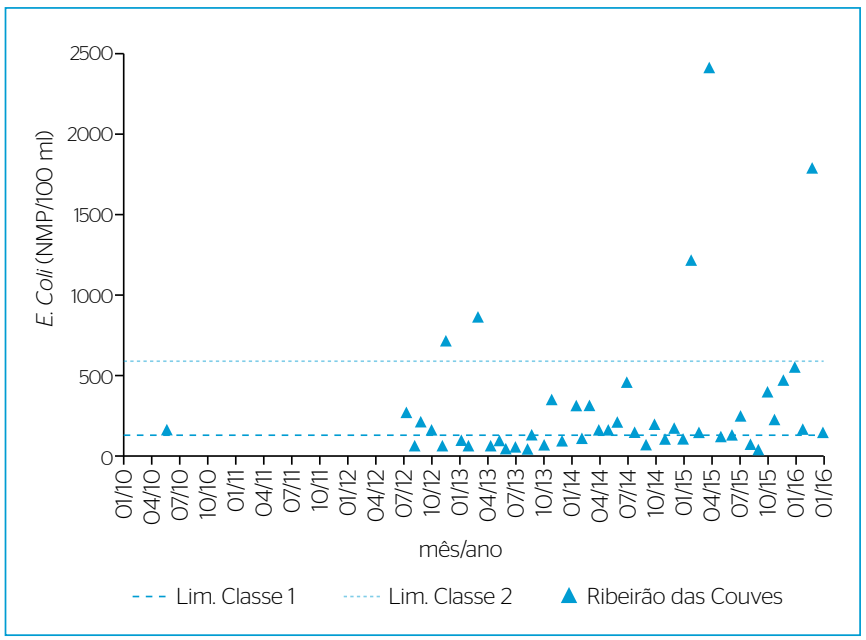

Figura 6 - E. Coli presentes nas águas do Ribeirão das Couves. reunir dados já existentes sobre a qualidade. Essas informações viabilizam o planejamento das ações de monitoramento.

$\mathrm{Na}$ fase de planejamento, realizam-se o diagnóstico, os projetos e a definição dos mecanismos legais e financeiros, e determinam-se os pontos e a frequência de amostragem, os parâmetros a serem analisados e o período de monitoramento. Além disso, de acordo com Mansur et al. (2013), é nessa fase que as primeiras caracterizações devem ser realizadas para servir de referência aos incrementos de qualidade obtidos com a implantação do PSA.

Os programas de PSA-H implantados no país possuem números distintos para os pontos de monitoramento, mas é possível verificar uma associação entre a quantidade de pontos e o tamanho das áreas. Essa densidade também é estabelecida pela Resolução nº 903/2012 da Agência Nacional de Águas (ANA), que cria a rede nacional de monitoramento no país. A maior densidade estabelecida pela referida resolução é de um ponto a cada 100 mil ha acrescido de mais um ponto em reservatórios estratégicos, como os utilizados para o abastecimento humano.

A alocação de três pontos nas áreas de cabeceira, intervenção e foz, como o estabelecido pela AGEVAP (2015), pode possibilitar o estabelecimento de referência de qualidade para áreas em que inexistam inventários. A densidade média dos pontos de monitoramento de PSA-H brasileiros, relacionados no Quadro 1, remetem a uma relação de 1 ponto a cada 880 ha (densidade mínima adotada como adequada para a fase de planejamento do projeto em estudo).

A verificação dos incrementos na qualidade das águas em áreas objeto de programas de PSA-H pode ser entendida como um dos indicadores de desempenho do programa. Assim sendo, os parâmetros a serem monitorados precisam estar relacionados com o uso dessas águas e devem ser inventariados por, no mínimo, um ano hidrológico.

Considerados os parâmetros mínimos de monitoramento da qualidade das águas estabelecidos pela Resolução ANA n 903/2012, os padrões d qualidade das águas estabelecidos pela Resolução CONAMA no 357/2005, os índices de qualidade usualmente empregados no país, tais como o IQA, o Índice Qualidade de Água Bruta para Fins de Abastecimento Público (IAP) e o Índice do Estado Trófico (IET), e, sobretudo, os parâmetros monitorados nos PSA-H implantados no país, infere-se que o monitoramento das águas deve contemplar, no mínimo, os seguintes parâmetros: $\mathrm{pH}$, oxigênio dissolvido (OD), condutividade elétrica, temperatura (água e ar) e turbidez. Além disso, esforços devem ser depreendidos para que os demais parâmetros de composição do IQA sejam avaliados, a fim de viabilizar equiparações das áreas contempladas por programas de PSA-H e demais áreas monitoradas pela rede nacional de monitoramento.

A frequência de monitoramento está diretamente associada à viabilidade de se correlacionar as ações de uso do território e as mudanças 
nas características físico-químicas das águas. No entanto, os custos associados à coleta e à análise dessas amostras remetem à adoção de frequências diferenciadas em função das fases do programa. A construção da linha de referência na fase de planejamento equivale a um monitoramento para inventário; desse modo, as análises devem ser realizadas mensalmente (ANA, 2016).

Na microbacia do Ribeirão das Couves, o monitoramento realizado pela SABESP ocorre em ponto localizado na exutória da área em estudo (774 ha). Assim sendo, a parceria institucional que viabilizou a disponibilização dos dados de monitoramento da qualidade das águas dos últimos cinco anos garantiu o estabelecimento de uma linha de referência, com frequência e temporalidade adequadas, para os parâmetros $\mathrm{pH}$, temperatura e turbidez. Os parâmetros OD e condutividade elétrica não foram contemplados pelo monitoramento da água bruta afluente à ETA, portanto precisam ser caracterizados antes da fase de implantação.

Durante a fase de implantação, na qual ocorrem as ações de recomposição florestal, saneamento, requalificação de usos e o efetivo pagamento aos proprietários das áreas, o monitoramento é semelhante à vigilância. De acordo com a ANA (2016), o monitoramento de vigilância demanda o aumento da frequência de amostragem para que as decisões sejam tomadas com a maior brevidade possível.

Consideradas as características hidrológicas, de uso e ocupação do território e, sobretudo, o controle dos potenciais impactos negativos à qualidade das águas durante a fase de implantação, convém que os pontos de amostragem de qualidade das águas sejam alocados para viabilizar o monitoramento das parcelas e da totalidade da área abrangida pelo PSA. Nas repartições de PSA-H implantadas no Brasil, em geral, as menores unidades de gestão são as propriedades rurais e as áreas totais estão associadas aos limites das bacias hidrográficas.

$\mathrm{Na}$ microbacia do Ribeirão das Couves, 4 das 8 propriedades aderiram ao PSA, o que representa cerca de $70 \%$ da área. Em três dessas propriedades estão previstas ações de manejo florestal. Assim sendo, considerado que o monitoramento da SABESP continuará a ocorrer com frequência mensal, sugere-se a realização de monitoramento mensal dos parâmetros: $\mathrm{pH}, \mathrm{OD}$, condutividade elétrica, temperatura (água e ar) e turbidez na saída de cada uma das propriedades. Além disso, nesse período devem ser realizadas as medições de OD e condutividade elétrica no ponto de monitoramento da SABESP.

$\mathrm{Na}$ fase de monitoramento, iniciada com a conclusão das atividades em campo e estendida, no mínimo, enquanto perdura o pagamento aos proprietários, o monitoramento pode ser classificado como básico. De acordo com a ANA (2016), esse monitoramento deve ser realizado em pontos estratégicos que permitam a identificação de tendências, com frequência de mensal a trimestral e por meio de parâmetros relacionados ao uso e à ocupação do território

O edital de chamamento aos proprietários rurais da microbacia do Ribeirão das Couves prevê o pagamento por serviços ambientais por um período de 24 meses prorrogáveis por igual período de tempo. Além disso, haverá continuidade de monitoramento das águas do Ribeirão das Couves pela SABESP. Para essa fase, foi proposta a realização de monitoramento trimestral nos pontos já avaliados na fase de implantação, além de sistematização e análise dos dados mensais da SABESP, preservando-se os parâmetros e métodos adotados na fase de implantação.

\section{CONSIDERAÇÕES FINAIS}

O PSA-H na microbacia do Ribeirão das Couves é reconhecido pelo poder público municipal como um projeto-piloto do Programa Mais Água, previsto para ser implantado na sub-bacia do Rio do Peixe, tributário da Bacia Hidrográfica do Rio Paraíba do Sul. O incentivo à preservação das áreas de vegetação nativa e a adoção de práticas sustentáveis na zona rural do município são objetivos do PSA em implantação, que visa a proteção dos recursos hídricos na região e o aumento da produção de água. $\mathrm{O}$ arranjo institucional coordenado pelo ente municipal envolve entidades públicas e privadas que contribuem para a estruturação e o monitoramento do PSA e, consequentemente, para a realização de suas ações.

Os dados da qualidade da água bruta, disponibilizados pela SABESP, permitiram verificar que as águas superficiais da microbacia do Ribeirão das Couves atende às condições de qualidade de águas para os parâmetros de turbidez e pH da Classe 1. Contudo, nessas águas a concentração de E. Coli é elevada e demanda a identificação das fontes de contaminação e a adoção de medidas de controle. Os dados avaliados foram utilizados para determinação de uma linha de referência para as demais fases do projeto, mas não contemplam todos os parâmetros entendidos como necessários à fase de planejamento do PSA.

A partir da pesquisa exploratória, o trabalho apresentou uma proposição de monitoramento da qualidade das águas para cada uma das fases do PSA-H, dada a escassez de recursos atestada nas experiências brasileiras antecessoras ao projeto. $\mathrm{O}$ aprofundamento dos estudos sobre indicadores da qualidade de águas em bacias hidrográficas contempladas por programas de PSA, assim como as significâncias e as especificidades dos parâmetros, são demandas que garantem a continuidade dos trabalhos de pesquisa, que deverão culminar na proposição de um IQA adaptado às unidades de PSA-H brasileiras. 


\section{REFERÊNCIAS}

AGEVAP - Associação Pró-Gestão das Águas da Bacia Hidrográfica do Rio Paraíba do Sul. (2015) PRO-PSA: Programa de Pagamento por Serviços Ambientais. 33p.

ANA - Agência Nacional de Águas. (2012a) Manual Operativo: Programa Produtor de Água. 2. ed. Brasília. 84p.

ANA - Agência Nacional de Águas. (2013) Resolução n. 0903, de 22 de julho de 2013. Cria a Rede Nacional de Monitoramento da Qualidade das Águas Superficiais - RNQA e estabelece suas diretrizes.

ANA - Agência Nacional de Águas. (2016) Rede nacional: redes de monitoramento. Disponível em: <http://portalpnqa.ana.gov.br/redenacional-rede-monitoramento.aspx>. Acesso em: 11 maio 2016.

APHA - American Public Health Association. (1998) Standard Methods for the Examination of Water and Wastewater. American Public Health Association, American Water Works Association, Water Environmental Federation. 20 ed. Washington, D.C.

BAUER, M.W. \& GASKELL, G. (2002) Pesquisa qualitativa com texto, imagem e som: um manual prático. Petrópolis: Vozes.

BRANCO, C. \& RUIZ, M. (2015) Pagamento por serviços ambientais: da teoria à prática. Rio Claro: ITPA.

BRASIL. (1986) CONAMA - Conselho Nacional do Meio Ambiente. Resolução n.o 20, de 18 de junho de 1986. Dispõe sobre a classificação e diretrizes ambientais para o enquadramento dos corpos de água, bem como estabelece as condições e padrões de lançamento de efluentes, e dá outras providências. Diário Oficial da União, Brasília.

BRASIL. (2004) Ministério da Saúde. Portaria n.o 518, de 25 de março de 2004. Estabelece os procedimentos e responsabilidades relativos ao controle e vigilância da qualidade da água para consumo humano e seu padrão de potabilidade, e dá outras providências. Revogada pela Port. ANVISA 2.914/2011. Brasília: Editora do Ministério da Saúde.

BRASIL. (2005) CONAMA - Conselho Nacional do Meio Ambiente. Resolução n.o 357, de 17 de março de 2005. Dispõe sobre a classificação dos corpos de água e diretrizes ambientais para o seu enquadramento, bem como estabelece as condições e padrões de lançamento de efluentes, e dá outras providências. Diário Oficial da União, Brasília.

BRASIL. (2011a) CONAMA - Conselho Nacional do Meio Ambiente. Resolução n. 0 430, de 13 de maio de 2011. Dispõe sobre as condições e padrões de lançamento de efluentes, complementa e altera a Resolução n.o 357, de 17 de março de 2005, do Conselho Nacional do Meio Ambiente-CONAMA. Diário Oficial da União, Brasília.

BRASIL. (2011b) Ministério da Saúde. Portaria n.o 2.914, de 12 de dezembro de 2011. Dispõe sobre os procedimentos de controle e de vigilância da qualidade da água para consumo humano e seu padrão de potabilidade. Diário Oficial da União, Brasília.
BRASIL. (2012) Lei n. ${ }^{0} 12.651$, de 25 de maio de 2012. Dispõe sobre a proteção da vegetação nativa. Diário Oficial da União, Brasília.

BRASIL. (2013) Ministério do Meio Ambiente. Lições aprendidas na conservação e recuperação da mata atlântica: planos municipais de conservação e recuperação da mata atlântica. Brasília: MMA. 100p.

CASTELLO BRANCO, M.R. Pagamento por serviços ambientais: da teoria à prática. Rio Claro (RJ): ITPA, 2015.

DE JULIO, M.; NEVES, E.F.A.; TROFINO, J.C.; DI BERNARDO, L. (2006) Emprego do reagente de fenton como agente coagulante na remoção de substâncias húmicas de água por meio da flotação por ar dissolvido e filtração. Revista de Engenharia Sanitária e Ambiental, Rio de Janeiro, v. 11, n. 3, p. 260-268.

FARLEY, J. \& COSTANZA, R. (2010) Payment for ecosystem services: from local to global. Ecological Economics, v. 69, p. 2060-2068.

FUNDAÇÃO GRUPO BOTICÁRIO DE PROTEÇÃO À NATUREZA. (2014) Protocolo de Indicadores de Impacto Ambiental e Socioeconômico para Projetos de Pagamento por Serviços Ambientais: Metodologia Oásis. 24p.

GALLOPIN, G.C. (1996) Environmental and sustainability indicators and the concept of situational indicators: a system approach. Environmental Modelling \& Assessment, n. 1, p. 101-117.

GOVERNO DO ESTADO DE SÃO PAULO. (1976) Decreto n.o 8.468, de 8 de setembro de 1976. Dispõe sobre a Prevenção e o Controle da Poluição do Meio Ambiente. São Paulo.

GOVERNO DO ESTADO DE SÃO PAULO. (1977) Decreto Estadual paulista n.o 10.755, de 22 de novembro de 1977. Dispõe sobre o enquadramento dos corpos de água receptores na classificação prevista no Decreto n. ${ }^{\circ}$ 8.468, de 8 de setembro de 1976 e dá providências correlatas. São Paulo.

GOVERNO DO ESTADO DE SÃO PAULO. (2002) Lei estadual n. ${ }^{\circ}$ 11.262, de 8 de novembro de 2002. Declaram Areas de Proteção Ambiental o trecho da Serra da Mantiqueira e as áreas urbanas no Município de São José dos Campos. São Paulo.

JARDIM, M.H. \& BURSZTYN, M.A. (2015) Pagamento por Serviços Ambientais na Gestão de Recursos Hídricos: o Caso de Extrema (MG). Revista de Engenharia Sanitária Ambiental, v. 20, п. 3, p. 353-360

LEITE, F.T. (2008) Metodologia científica: métodos e técnicas de pesquisa (monografia, dissertação, teses e livros). Aparecida: Ideias \& Letras.

LIMA, A.P.M.; ALBUQUERQUE, R.H.; PRADO, R.B.; TURETTA, A.P.D; FIDALGO, E.C.C.; SCHULER, A.E. (2013) Pagamento por Serviços Ambientais Hídricos no Brasil: experiências iniciais e os desafios do monitoramento. In: Simpósio Brasileiro de Recursos Hídricos, 20., Bento Gonçalves. Anais... Bento Gonçalves. 
LIMA, A.P.M.; PRADO, R.B.; SCHULER, A.E.; FIDALGO, E.C.C. (2O15) Metodologias de monitoramento de Programas de Pagamento por Serviços Ambientais Hídricos no Brasil. In: Simpósio Brasileiro de Recursos Hídricos, 21., Brasília. Anais... Brasília.

MANSUR, H.; GUIMARÃES, J.; KLEMZ, C. Estudo de viabilidade de implantação do programa PRO-PSA na região Hidrográfica do Guandu - RJ. Rio de Janeiro: Programa de Conservação da Mata Atlântica e Savanas Centrais, 2013.

MARSHALL, G.R. (2013) Transaction costs, collective action and adaptation in managing complex social-ecological systems. Ecological Economics, v. 88, p. 185-194.

MATTOS, L. \& HERCOWITZ, M. (2011) Economia do meio ambiente e serviços ambientais: estudo aplicado à agricultura familiar, às populações tradicionais e aos povos indígenas. Brasília: Embrapa. 294p.

MINAYO, M.C.S.; ASSIS, S.G.; SOUZA, E.R. (Orgs.). (2005) Avaliação por triangulação de métodos: abordagem de programas sociais. Rio de Janeiro: Fiocruz.

MURADIAN, R.; COBERA, E.; PASCUAL, U.; KOSOY, N.; MAY, P.H. (2010) Reconciling theory and practice: an alternative conceptual framework for understanding payments for environmental services. Ecological Economics, v. 69, p. 1202-1208.

NOVAES, R.M.L. (2014) Monitoramento em Programas e Políticas de Pagamentos por Serviços Ambientais em Atividade no Brasil. Estudos, Sociedade e Agricultura, Rio de Janeiro, v. 22, n. 2, p. 408-431.

OMS - Organización Mundial de la Salud. (1995) Guías para la calidad del agua potable. Genebra: OMS.
PAGIOLA, S.; GLEHN, H.C.V.; TAFARELLO, D. (2012) Experiências de pagamentos por serviços ambientais no Brasil. São Paulo: Secretaria do Meio Ambiente. 336p.

PEREIRA, P.H. (2012). Conservador das águas- Extrema. In: PAGIOLA, S.; GLEHN, H.C.V:; TAFFARELLO, D. (Org.). Experiências de pagamentos por serviços ambientais no Brasil. São Paulo: SMA/ CBRN. p. $29-42$.

SATO, M.I.Z; HACHICH, E.M.; MENEGOM JR., N.; MELO, A.M.J.; COELHO, M.C.L.S.; DIBARI, M.; RAMOS, S.R. (2008) Relatório técnico: monitoramento de Escherichia coli e coliformes termotolerantes em pontos da rede de avaliação da qualidade de águas interiores do Estado de São Paulo. São Paulo: Diretoria de Tecnologia, Qualidade e Avaliação Ambiental. Departamento de Análises Ambientais.

SÃO JOSÉ DOS CAMPOS. (2014) Projeto Mais Água. Apresentado pela Secretaria Municipal do Meio Ambiente da Prefeitura de São José dos Campos à AGEVAP (Agência de Bacias) conforme Edital O4 de 2014. São José dos Campos.

TNC - The Nature Conservancy. (2011) Protocolo de Monitoramento de Água e Solos: Programa Produtor de Água.

TNC - The Nature Conservancy. (2013) Termo de Referência: Monitoramento de Qualidade de Água na Bacia Hidrográfica do Rio Camboriú Projeto Produtor de Água do Rio Camboriú.

VON SPERLING, M. (2005) Introdução à qualidade das águas e ao tratamento de esgotos. Belo Horizonte: Universidade Federal de Minas Gerais, Departamento de Engenharia Sanitária e Ambiental.

WUNDER, S. (2005) Payments for environmental services: some nuts and bolts. CIFOR Occasional Paper, n. 42. 24p. 